University of Nebraska - Lincoln

DigitalCommons@University of Nebraska - Lincoln

2-1968

\title{
Floral Development and Vasculature in Hydrocleis nymphoides (Butomaceae)
}

Robert B. Kaul

University of Nebraska-Lincoln

Follow this and additional works at: https://digitalcommons.unl.edu/bioscifacpub

Part of the Biology Commons, and the Botany Commons

Kaul, Robert B., "Floral Development and Vasculature in Hydrocleis nymphoides (Butomaceae)" (1968). Faculty Publications in the Biological Sciences. 847.

https://digitalcommons.unl.edu/bioscifacpub/847

This Article is brought to you for free and open access by the Papers in the Biological Sciences at DigitalCommons@University of Nebraska - Lincoln. It has been accepted for inclusion in Faculty Publications in the Biological Sciences by an authorized administrator of DigitalCommons@University of Nebraska - Lincoln. 


\title{
Floral Development and Vasculature in Hydrocleis nymphoides (Butomaceae)
}

\author{
Robert B. Kaul \\ Department of Botany, University of Nebraska, Lincoln
}

\begin{abstract}
The flower of Hydrocleis nymphoides consists of three sepals which arise in spiral succession, three simultaneously arising petals, numerous stamens and staminodia which arise in centrifugal order, and six carpels. A residual apex remains at maturity. The first-formed members of the androecium are stamens and the later-formed members are staminodia which develop below the stamens and which become outwardly displaced during expansion of the receptacle. The androecium is supplied by branching vascular trunk bundles. The carpels are completely open but the ventral margins are slightly conduplicately appressed basally. A single dorsal bundle provides the stigmatic area with vascular tissue, and a network of small placental bundles supplies the numerous laminar ovules. There are no clearly defined ventral bundles. It is suggested that Hydrocleis nymphoides is neither the most primitive nor the most advanced member of the family. A pattern of phylogenetic reduction in the androecium and receptacle is suggested for the entire family.
\end{abstract}

The Butomaceae is sometimes considered to comprise four genera: Butomus, Tenagocharis, Hydrocleis, and Limnocharis. A fifth genus, Ostenia, is sometimes included but according to Pedersen (1961) all of the characteristics of that genus can be found within
Hydrocleis and he therefore suppressed the name Ostenia. All of the genera except Hydrocleis are monotypic.

Stant (1967) has studied the vegetative anatomy of the entire family and has reviewed the pertinent literature. Certain features of the structure and development 
of the flowers in the family have not been studied, and investigations of floral morphology and ontogeny in $\mathrm{Hy}$ drocleis have centered upon H. nymphoides Buch. Saunders (1929) illustrated some aspects of the anatomy of the gynoecium, and Ronte (1891) and Eber (1934) have reported some of the developmental features of the flowers. Almost nothing is known of the structure of the other species of the genus. The present study has been undertaken to try to delineate and clarify some of the developmental relationships, particularly in the androecium and gynoecium, to correlate the vascular pattern with the external morphology, and to attempt to ascertain the phylogenetic status of some of the morphological characters. By providing a basis for comparison with similar studies in other genera of the family (Kaul, 1967) it is hoped that a better understanding of the actual phylogenetic status of the family can be achieved.

The flowers of the nine species of Hydrocleis show several meristic variations. There are usually six carpels in $H$. nymphoides, three in H. grosourdyana, and four or five in H. cryptopetala. Hydrocleis nymphoides has about 25 stamens and numerous staminodia, while $H$. martii has about 12 stamens and numerous staminodia. Hydrocleis uruguayensis has six and $H$. modesta three stamens, both without staminodia. Hydrocleis parvifiora has six to eight staminodia and $H$. standleyi has two or three. I have studied only $H$. nymphoides.

\section{Materials and Methods}

Inflorescences in all stages of development were preserved in FAA. The plants were obtained commercially and grown in the greenhouse. Flowers from the larger inflorescences were embedded in paraffin separately, while entire smaller inflorescences were embedded whole. Both cross and longitudinal sections were made in various thicknesses, and they were stained with safranin and fast green or with crystal violet and fast green. Numerous clearings were made by placing all but the smallest flower primordia in $5 \% \mathrm{NaOH}$ overnight in the $60{ }^{\circ} \mathrm{C}$ paraffin oven, rinsing, and either transferring them to lactic acid without staining or staining them in crystal violet and fast green and storing them in xylene for study. The flowers cleared rapidly and well by these methods. About 100 flowers were examined.

\section{Observations}

Hydrocleis nymphoides is a plant of shallow fresh water distributed from Central America south to northern Argentina. It is sometimes grown as an aquatic ornamental and is sold under the name waterpoppy. The leaf blades float upon the water surface or project slightly above it, and the petioles and stolons float just beneath the surface. The plant spreads rapidly by the stolons and roots readily at the nodes. The clear yellow flowers are held slightly above the surface, and each is borne in the axil of a large bract. The very short internodes between the bracts create an indeterminate umbel whose vegetative apex later produces leaves and then the single long stoloniferous internode. The perianth consists of three spongy green sepals and three large yellow petals (Figure 1). The androecium consists of numerous fertile stamens, with purple filaments and yellow anthers, which are surrounded by numerous purple staminodia. The six carpels are yellow at the base shading to maroon at the top. Each carpel is weakly differentiated into stigmatic area, style, and ovary. The stigmatic region extends some distance down the unfused ventral carpel margins (Figure 8).

\section{Floral ontogeny}

The earliest evidence of a developing flower can be seen immediately behind the vegetative apex where the appearance of the bract primordium is followed closely by the appearance of the floral apex (Figure 2). The vegetative apex consists of two tunica layers over a prominent corpus (Figures 2, 3). The very young floral primordium, as seen in Figure 2, has a similar construction but it soon develops a third tunica laver. The three tunica lavers remain prominent throughout the life of the flower and they persist in the residual floral apex (Figures 3-7). The first floral appendages appear at the same time the third tunica layer is differentiating (Figure 4).

The three sepals arise successively in spiral order. The petal primordia appear simultaneously and they are alternate with the sepals. They appear at about the same time as the first stamen primordia. The first stamens arise simultaneously as a whorl of six primordia evenly distributed about the circumference of the apex and some distance above the petal primordia (Figure 9). No stamen primordium is opposite the median portion of a perianth member. Instead, these first stamens appear in what can be interpreted as pairs opposite the sepals. Appearance of each stamen primordium is presaged by divisions in the second and third tunica layers (Figure 4). The second whorl of stamens arises alternate with the first whorl and slightly below it (Figure 9). The third whorl is alternate with, and below, the second, and it is therefore directly beneath the first whorl. Subsequent stamens and, later, staminodia follow this centrifugal sequence. Their numbers obscure any whorled pattern which might be present, and the total effect is that of a spirally arranged androecium.

The single whorl of six carpels arises coincident with the appearance of the second and third whorls of stamens and its members are alternate with the six stamens of the first whorl and opposite the perianth members (Figure 9). The carpels are completely open at maturity but there is a tendency toward conduplicate appression (Figure 8). Differentiation of the stigmatic areas occurs late in carpel ontogeny and there is a slight 


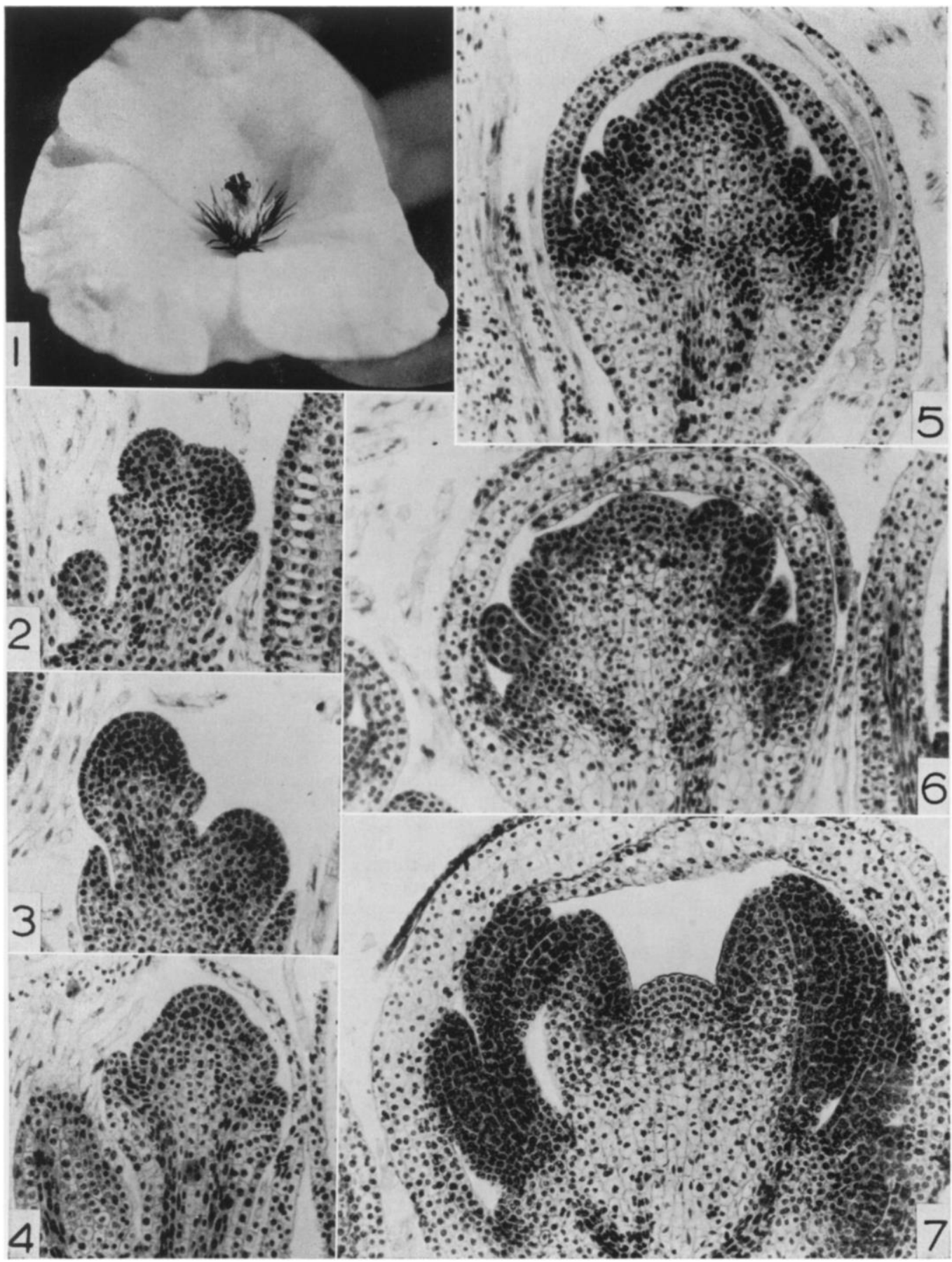

Figure 1. Flower at anthesis, X 1.2. | Figure 2. Inflorescence apex with young flower primordium emerging on the left, X 140. | Figure 3. Somewhat older phase in which the flower primordium has become clearly differentiated. Early sepal primordium has appeared on the right side of the floral bud, X 120. | Figure 4. Perianth is developing, with a sepal primordium on the left and a petal primordium on the right, both with procambium. The first stamens are emerging just above the perianth. The third tunica layer is becoming evident at this stage. Cell elongation is evident in the pedicel, and recently formed daughter nuclei are evident in the upper part of the parenchymatous core, X 100. | Figure 5. Older stage, comparable with Figure 9. Several whorls of stamens have appeared, and the earliest evidence of carpel primordia is shown. Prominent radial seriation of procambial cells is seen in the pedicel, which is still elongating, X 160. | Figure 6. Older stage, with carpel primordia well defined, X 150. | Figure 7. Still older stage, comparable with Figure 10. Residual apex with its three tunica layers is prominent between the carpel primordia. First-formed, upper stamens now considerably larger than later-formed stamens, X 150. 
stylar constriction of the carpel walls above the ovuliferous areas. Each carpel primordium is meristematic throughout until maturity. Divisions in the abaxial and adaxial protoderm are anticlinal, and growth is diffuse throughout the remainder of the primordium.

There are no prominent marginal meristems. The ovules arise by periclinal divisions in the first and second sub-protodermal layers. The protoderm over each ovule primordium continues to divide only anticlinally during ovule development. Ovules appear first on the lower middle portion of the carpel walls well before the carpel has reached full size. Subsequent appearance of ovules is rapidly acropetal and basipetal from the first ones. The carpel bases are decurrent upon the somewhat elongate receptacle, and a prominent residual floral apex is seen among them at maturity (Figures 7 and 10).

The first-formed stamens are for a time taller than the subsequently formed ones and the staminodia (Figures 7 and 10), but eventually the staminodia and outer stamens overtop them (Figure 1). The stamens mature in the order in which they appear, however. Maturation of the androecium is accompanied by the development of androecial shoulders so that the last-formed staminodia are somewhat outside of, rather than below, the inner members. The development of these shoulders is illustrated in Figures 5-7 and Figures 9 and 10.

While the sepals achieve their mature size some time before anthesis, the petals remain relatively small until just prior to anthesis, when they undergo enormous expansion due mostly to cell enlargement.

\section{Vascular anatomy}

The vasculature of the mature flower consists of two major independent systems and of two minor systems. The major systems are represented in the pedicel by six large bundles near the center (Figure 11). The three bundles opposite the sides of the roughly triangular pedicel supply the calyx (Figure 11, white bundles) and the three opposite the corners supply the corolla, androecium, and gynoecium (Figure 11, black bundles). Each sepal bundle branches into three major branches in the base of the receptacle. The central branch becomes the sepal median bundle, and the other two proceed horihorizontally in the receptacle and throw off small branches into the sepal. The horizontal branches are weakly anastomosed with similar branches from adjacent sepals in the corners of the receptacle (Figure 11).

The three inner bundles opposite the corners of the pedicel become united into a ring of vascular tissue at about the same level as the branching of the sepal bundles (Figure 11). A petal median bundle departs from the lower part of this ring into each petal. Above the departure of these three petal median bundles the stamen and carpel supplies separate from the ring: six bundles continue to the gynoecium, one to each carpel, and nine supply the androecium. The androecial bundles divide several times and supply each stamen and staminodium with a single bundle (Figure 11). A single bundle enters the base of each carpel and divides tangentially once. The abaxial derivative, the dorsal bundle, continues without branching into the stigmatic region where it branches several times and supplies both stigmatic arms (Figure 8). The inner derivative continues up the ventral margins of the carpel and divides just below the level of separation of the ventral carpel margins from the receptacle. Each of the two branches soon loses its identity as it supplies a carpel wall with a meshwork of placental bundles (Figure 8 ). Thus there are no clearly defined ventral bundles. The ovules are scattered over the carpel walls except along the dorsal bundle and toward the ventral edges. There is a small area between the ovuliferous walls and the stigmatic area which represents a weakly defined style (Figure 8 ). There are no residual vascular bundles in the receptacle.

Both of the minor vascular systems supply the perianth. One of these systems is represented in the pedicel by numerous small bundles located near the periphery. These tiny bundles enter the sepals and provide the network of small bundles found on the abaxial sides of those organs. This system is not illustrated in Figure 11. The other minor vascular system supplies the petals with most of their small bundles. It is represented in the pedicel by a single bifurcating bundle located in each angle of the pedicel internal to the tiny peripheral bundles serving the sepals but greatly external to the large inner bundles of the major vascular system (Figure 11). The branches of these petal bundles enter the petals roughly parallel with the median bundles from the major vascular system (Figure 11). They are occasionally anastomosed in the receptacle with the nearby major sepal bundles.

Differentiation of procambium appears to be acropetal and continuous throughout the flower. The procambial strands reach the perianth while its primordia are barely visible, but stamens and carpels are not vascularized until they are about one-third grown.

\section{Discussion}

The flower of Hydrocleis nymphoides exhibits a number of features considered primitive: numerous stamens, open carpels with decurrent stigmatic crests and laminar placentation, a prominent residual floral apex topping a relatively elongate receptacle, and a lack of fusions. The phylogenetic status of centrifugal stamen development is unclear. It is known in the dicotyledons in several families, some of which (for example, Dilleniaceae, Cactaceae) are at least moderately primitive, but among the monocotyledons it is known only in Hydrocleis nymphoides and in Limnocharis flava (Kaul, 1967). Presumably it occurs in other species of Hydrocleis . Its 

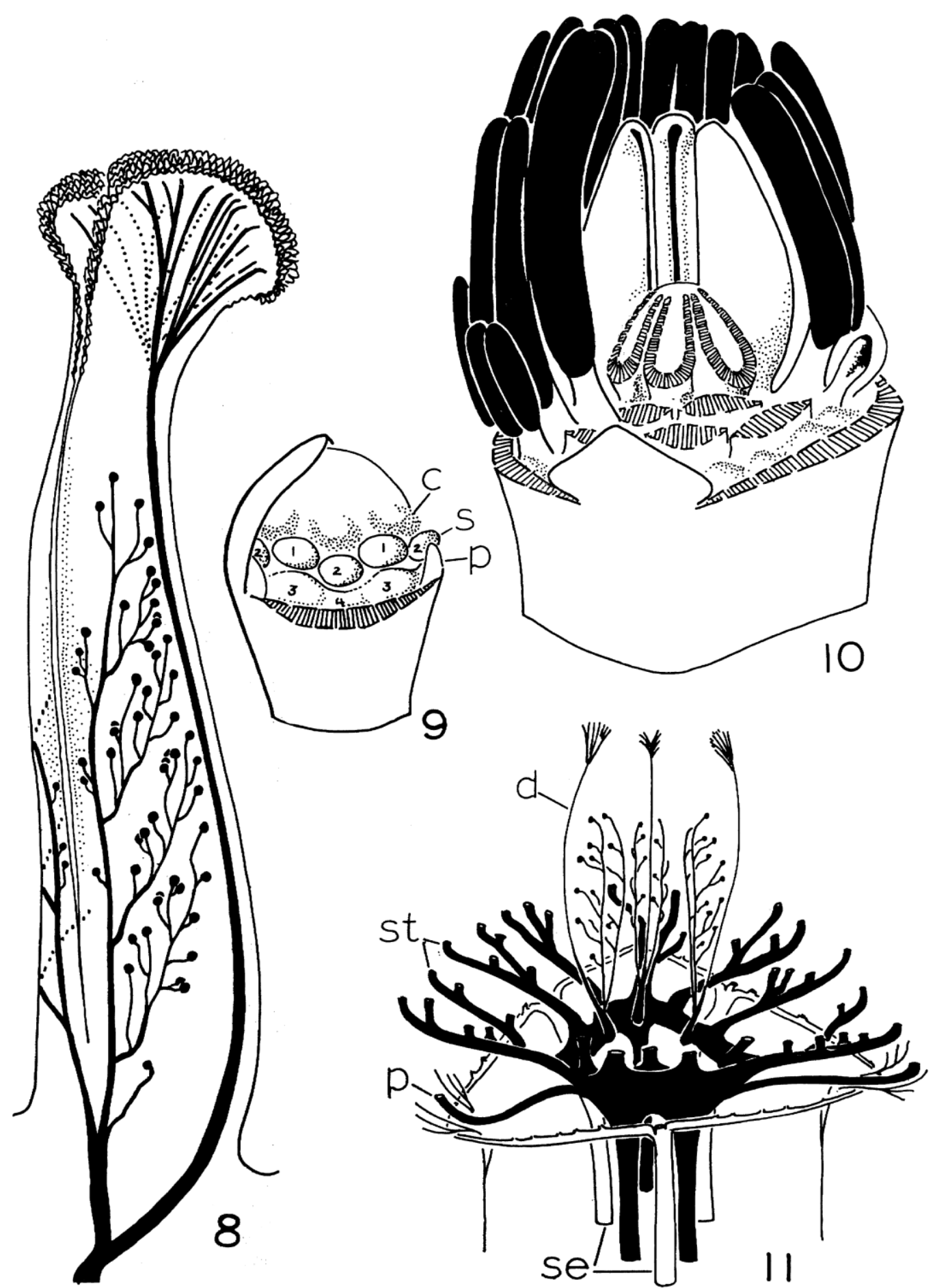

Figure 8. Mature carpel, completely open above the receptacle, with ventral margins slightly conduplicately appressed. Black dots indicate points of attachment of ovules at the ends of tiny placental bundles, X 15. | Figure 9. Floral bud just after carpel initiation. Stamen whorls numbered in order of their appearance, X 120. | Figure 10. Floral bud at beginning of staminodium initiation and some time before anthesis. Three carpels removed to expose residual floral apex. Outer stamens and staminodia will eventually overtop the inner stamens. The open carpel primordia have not yet begun differentiation of the stigmatic areas or of ovules. Staminodial primordia stippled, X 65. | Figure 11. Vascular system of mature flower. The system shown in white serves the sepals, that shown in black serves the petals, androecium, and gynoecium. There is no residual vascular tissue above the carpels. Bundles serving the androecial members are shown cut off for simplification, $X$ 16.-c, carpel primordium; $d$, dorsal bundle; p, petal primordium or petal median bundle; s, stamen primordium; se, sepal bundle; st, androecial trunk bundle. 
frequent association with primitive characters suggests that it is a primitive feature, too.

Investigations of the androecium of the Butomaceae have centered upon Butomus, and for the most part other genera have been neglected. Salisbury (1926) examined hundreds of flowers of Butomus and agreed with the interpretation that its pairs of stamens opposite the sepals represent congenital splitting of a trimerous whorl (dedoublement), while the single stamen opposite each petal had not undergone such a splitting. A similar disposition of nine stamens is found in Tenagocharis latifolia. The independent origin of the vascular bundle to each stamen of Butomus and Tenagocharis (Kaul, 1964) does not support the splitting theory. The bundles depart independently from the receptacular vascular plexus and proceed without fission to the stamens.

Ronte (1891) observed that the very numerous stamen and staminodial primordia of Limnocharis flava and Hydrocleis nymphoides arise independently of each other and he believed that this fact weighs heavily against the splitting theory. Buchenau (1903), on the basis of Ronte's observations, interpreted the androecia of Butomus and Tenagocharis as reductions from a Limnocharis-Hydrocleis type by a phylogenetic loss of stamens.

The tendency toward sterilization of the outer members of the androecium of Limnocharis flava (Kaul, 1967) and Hydrocleis nymphoides suggests a reduction pattern which could lead to the Butomus-type androecium. In Hydrocleis nymphoides the first whorl of stamens to arise, the inner one, is alternate with the carpels (Figure 9) and the second whorl is opposite them. The stamens of the first whorl are therefore disposed in such a way that they appear to arise in pairs opposite the sepals. Progressive phylogenetic sterilization and loss of stamens from the outside could lead to the Butomus pattern in which only the inner stamens remain. Sterilization and loss of the upper, last-formed stamens is the primitive condition in the dicotyledon, according to Eames (1961). In Hydrocleis nymphoides and Limnocharis flava it is the last-formed, but morpho-

\section{Literature Cited}

Buchenau, F. 1903. Butomaceae, pp. 1-12. In A. Engler [editor], Das Pflanzenreich IV (16). W. Engelmann, Leipsic.

Eames, A. J. 1961. Morphology of the angiosperms. McGraw Hill, New York.

Eber, E. 1934. Karpellbau und Plazentationsverhältnisse in der Reihe der Helobiae. Flora 127: 273-330.

Kaul, R. B. 1964. A phylogenetic study of the flowers of the Butomaceae and the Hydrocharitaceae. Ph.D. thesis, University of Minnesota. logically lowest, stameris which are transformed. The innermost whorl of stamens of Hydrocleis nymphoides is of extreme interest in this regard for it would be the last remaining whorl in such a transformation. It is possible that further evidence for such a reduction pattern will be found within the genus Hydrocleis in a study of those species which exhibit fewer and more definite numbers of stamens and staminodia than are found in $H$. nymphoides.

The reduction in number of stamens and carpels within the family is associated with progressive phylogenetic shortening of the receptacle. The elongated receptacle of Limnocharis flava is the most primitive within the family (Kaul, 1967). Hydrocleis nymphoides and Tenagocharis have less elongated receptacles, and Butomus has the shortest. Troll (1932) hypothesized a type of receptacle intermediate between those of Limnocharis and Butomus. This intermediate type is found in Hydrocleis nymphoides and Tenaqocharis.

The alignment of genera within the Butomaceae is problematical. Pichon (1946) believed that the Butomaceae should include only Butomus and that the other genera should be transferred to an enlarged Alismataceae. He particularly cited the pollen of Butomus, which is unlike that of the other genera of the family. Rao's (1953) cytotaxonomic study of the family suggests that Butomus is the most distinct genus of the four. Maheshwari (1955) found Butomus to be embryologically distinct from the other genera. Stant (1967) concluded, on the basis of anatomical studies of vegetative organs, that Butomus is clearly distinct within the family, that Hydrocleis and Limnocharis are anatomically the most similar members of the family, and that the Butomaceae and Alismataceae are closely related. My study of the flowers of the four genera leads me to conclude that Butomus and Tenagocharis have many structural similarities and that Hydrocleis and Limnocharis are more similar to each other than they are to the other two genera. The Limnocharis flower is, however, more primitive than that of Hydrocleis nymphoides.

Kaul, R. B. 1967. Ontogeny and anatomy of the flower of Limnocharis flava (Butomaceae). American Journal of Botany 54: 1,223-1,230.

Maheshawari, P. 1955. The occurrence of hisporic embryo sacs in angiosperms: a critical review. Phytomorphology 5: 67-99.

Pedersen, T. M. 1961. New species of Hydrocleis, Scirpus, and Stellaria. Botanisk Tidsskrift 57: 38-46.

Pichon, M. 1946. Sur Jes Alismatacées et Jes Butomacées. Notulae systematicae 12: 3-4. 
Rao, Y. S. 1953. Karyo-systematic studies in Helobiales. I. Butomaceae. Proceedings of the National Institute of Sciences India 19: 563-581.

Ronte, H. 1891. Beitrage zur Kenntnisse der Blüthengestaltung einiger Tropenpflanzen. Flora 49: 492529.

Salisbury, E. J. 1926. Floral construction in the Helobiales. Annals of Botany 40: 419-445.
Saunders, E. 1929 On carpel polymorphism. III. Annals of Botany 43: 459-481.

Stant, M. Y. 1967. Anatomy of the Butomaceae. Journal of the Linnean Society of London 60: 31-60.

Troll, W. 1932. Beiträge zur Morphologie des Gynaeceums II. Über das Gynaeceum von Limnocharis Humb. et Bonpl. Planta 17: 453-460. 